\title{
Use of Tablets in Moroccan Primary School Inventory and Impact of Teacher Training
}

\author{
E. A. Rahali, A. Chikhaoui, K. E. Khattabi, and F. Ouzennou
}

\begin{abstract}
Since the 2000s, the leaders of Moroccan educational system called for the introduction of information and communication technology means in education. Thus, the majority of primary schools have been equipped with computers and internet connection. But when it comes to tablets, Moroccan schools are only in the early stages of experimentation. This article aims, on the one hand to probe the inventory of places of use of this artefact in classroom practice and to elucidate the obstacles that could constrain its effective and efficient use; on the other hand, to study the impact of teacher training on the perceived value of this artefact in educational practice. So, we carried out research via a questionnaire and semi-structured interviews in 13 schools that received endowments of 11 to 16 tablets each. The results showed that the use of tablets is very limited; and suffers from several obstacles that hinder its integration. And that the technical and pedagogical training of teachers is a major factor in the perceived usefulness of this technology in classroom practice.
\end{abstract}

Index Terms-Primary education, use of tablets, teacher training, perception of utility.

\section{INTRODUCTION}

Since its arrival on the market in 2010 [1], the digital tablet by its innovative character has aroused the interest of the educational sphere around the world. This mobile, tactile and connected artefact, which brings together the capacities of a computer and the lightness and connectivity of a smartphone, gives rise to several states of use, or affordances [2]. Researchers identified five affordances: "portability, generalization, the possibility of located and 'just in time' learning, connectivity and convergence, and the possibility of individualized and personalized practices" [3]. These pedagogical and technical affordances have been the subject, over the past ten years, of several field studies, most of them showing a positive impact both on pedagogical and didactic choices for the teacher and on the learning power of the learner [2]-[5]. two literature reviews, one conducted on 23 studies in 2016 and the other conducted on 41 studies in 2019 showed a positive effect of tablets on learning [6], [7]. Thus, the tablet has found a place in teaching practice in most countries of the Organization for Economic Co-operation and

Manuscript received May 31, 2021; revised June 18, 2021.

El Ayachi Rahali is with University Sidi Mohamed Ben Abdellah (USMBA), Fez. He is also with the Regional Center for Education and Training in Béni Mellal. Morocco (email: elayachi.rahali@usmba.ac.ma).

Ahmida Chikhaoui and Khalid El Khattabi are with University Sidi Mohamed Ben Abdellah (USMBA), Fes, Morocco (e-mail: ahmida.chikhaoui@usmba.ac.ma,khalid.elkhattabi2018@gmail.com).

Fatima Ouzennou is with the Regional Center for Education and Training in Fes, Morocco (e-mail: fatima.ouzennou@gmail.com).
Development [8]. In the USA, for example, the number of students using digital tablets for educational purposes increased from 4.5 million in 2013 to more than 7 million in 2015; and in Quebec during the same period, the number has multiplied by 9 increasing from 10,000 to 90 [1], [9].

Faced with this technological advent, the Moroccan higher council for education, training and scientific research, in its report "Rethinking and rebuilding the Moroccan school, strategic vision (2015-2030)", called among others to renovate the teaching profession (lever 9), by providing educational institutions with the necessary equipment (lever 6) to establish an efficient and attractive school (lever 7) [10]. To do this, this strategic vision emphasizes the recourse to the means of information and communication technologies, including the use of tablets. Thus, two endowments were made as part of the Samsung Smart School project during the 2017-2018 and 2018-2019 school years, during which cases of 11 to 16 tablets were distributed to primary schools in the kingdom. During the covid 19 pandemic, some regional education and training academies provided their learners with a limited number of tablets to ensure educational continuity. But none of these endowments to our knowledge have been the subject of a study that could follow up an analysis of the impact of the integration of this technology on the teaching-learning process. Through this research, our ambition is to elucidate the inventory of the use of tablets in Moroccan primary education, and to assess the impact of teacher training on the acceptance of the introduction of this artefact into classroom practice.

\section{RESEARCH QUESTIONS}

To achieve the above objectives, we formulated the following research questions:

- What are the teaching practices related to the use of the tablet in a Moroccan primary school context?

- What is the impact of training in the acceptability of tablets in school context by primary school teachers?

- What are the obstacles that hinder the integration and use of tablets in classroom practice at the Moroccan primary school?

\section{Methodology}

\section{A. Research Site}

To answer the previous research questions, we had to find an educational ecosystem where the Moroccan education system made use of digital tablets for teachers. Indeed, within the framework of an agreement between the Ministry of 
National Education, Vocational Training, Higher Studies and Scientific Research, on the one hand, and the company "Samsung Maghreb Arab" on the other hand , 200 primary schools throughout the kingdom were provided with tablet cases according to a project called "Samsung Smart School": 100 schools benefited from cases containing 11 tablets each during the 2017-2018 school year; and 100 schools benefited from suitcases containing 16 tablets during the 2018-2019 school year. Each school has appointed a referent teacher who has benefited from a three-day technical and pedagogical training; and has been responsible for increasing training at the level of his institution for the benefit of his colleagues.

This research was carried out in the region of Béni Mellal Khénifra: one of the 12 regions of the country. The target audience are teachers in public primary schools, working under the supervision of the Beni Mellal regional academy. This region encompasses five provinces. Number of beneficiary schools is 13 , at a rate of two to three schools per province, in which 282 teachers work; $50.71 \%$ of them are women (Fig. 1 and Fig. 2).

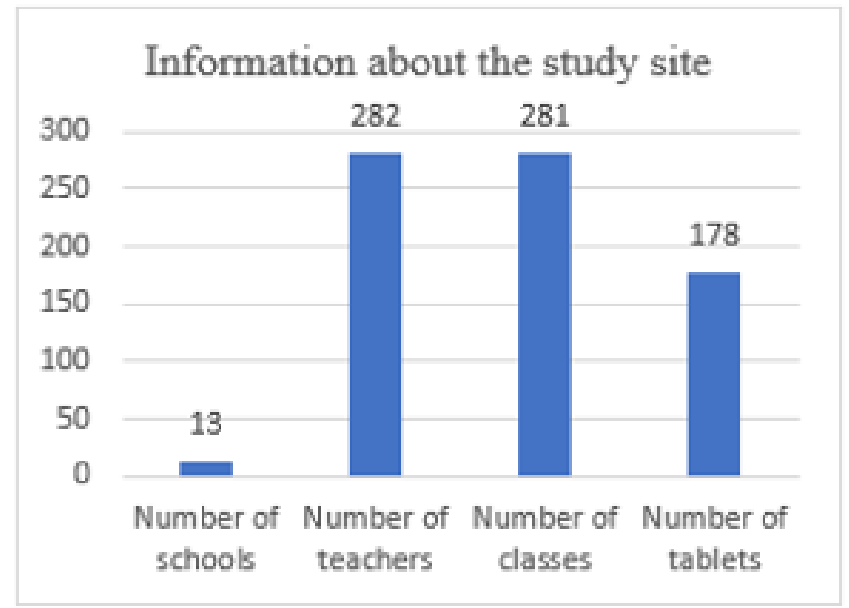

Fig. 1. Information about the study site.

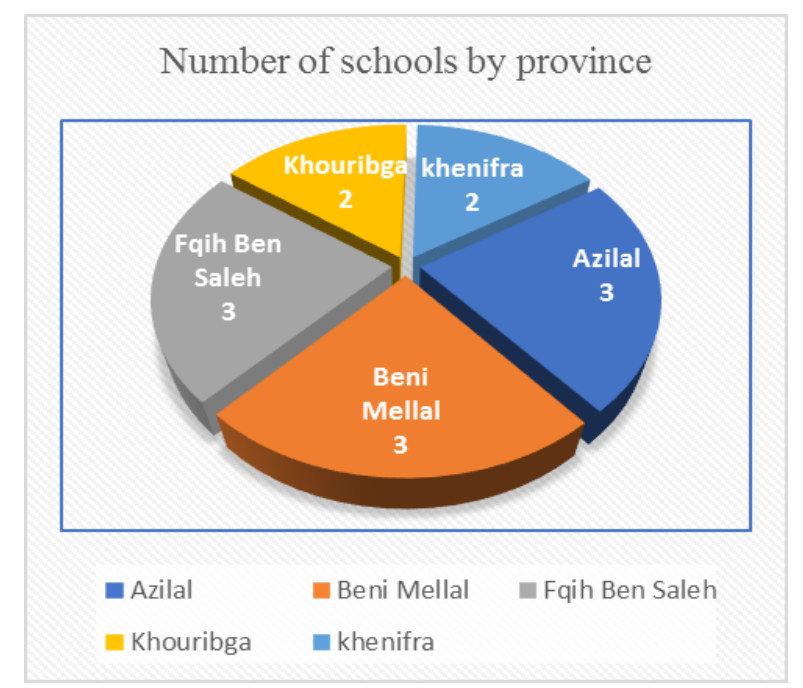

Fig. 2. Number of schools by province.

This study, which took place between March and June 2020 , therefore comes after an experiment ranging from two to three years; period that we considered sufficient for the experimental teachers to have a clear idea about the use of digital tablets in classroom practice.

\section{B. Participants}

The participants in this study are all teachers from the 13 schools mentioned above. We contacted these schools through the regional academy, which gave us permission to access them and collect the necessary data for this research. We found that teachers from these schools have formed a WhatsApp group dedicated to sharing information, knowledge and know-how regarding the use of digital tablets in educational practice. It was through this group that a questionnaire of 16 items was administered. The number of respondents reached 48: (80.9\% men and $19.1 \%$ women) of different ages (Fig. 3).

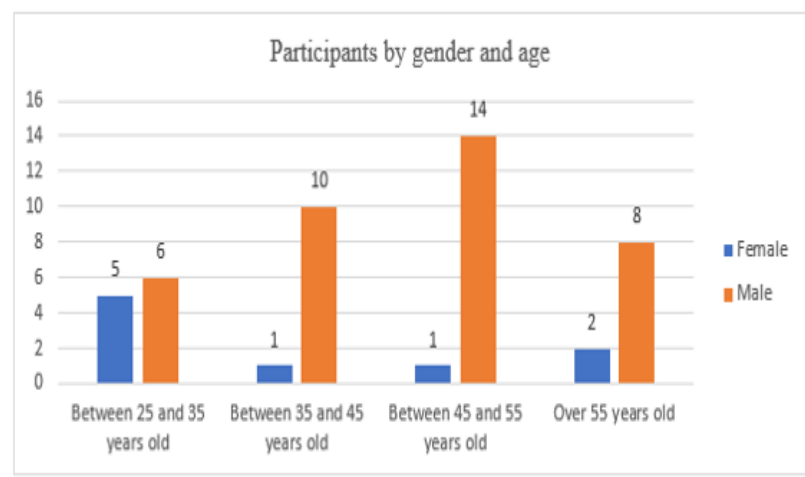

Fig. 3. Participants by gender and age.

Then, we held semi-structured individual interviews with 10 teachers randomly selected from five of the 13 beneficiary schools, at the rate of two teachers per school and per province. These interviews aimed to deepen the understanding of the data obtained by the questionnaire, and to highlight the perceptions of teachers towards the introduction and use of tablets in the teaching practice of Moroccan primary education and the factors that influence it.

This methodological triangulation bringing together two measurement instruments allowed us to "compensate for the specific biases to each instrument, and to ensure the validity of the analysis carried out" [11]. The questionnaire, consisting of questions aimed at collecting quantitative and other qualitative data, was administered online via the "Soorvey" survey platform. The semi-structured individual interviews were conducted by telephone with 10 teachers randomly selected from five schools selected at random from the five provinces in the region, at the rate of one school per province. The use of the telephone as a medium for the interview was dictated by the state of sanitary confinement inflicted by the Covid 19 pandemic. All responses to the questionnaire, such as interviews, were anonymous.

\section{Data Analysis}

The quantitative data from the questionnaire were analysed by the SPSS 22 software. And the data collected from the open-ended questions of the questionnaire and from the interviews were processed manually. The reliability of the questionnaire was verified by Cronbach's alpha coefficient for the items concerned [12], [13]. The correlations are highlighted by Pearson's chi-square calculation and, failing that, by Fisher's exact test [14], [15]; and the possible relationship strengths are shown by Cramer's V coefficient [14]. 


\section{Technical Characteristics of the Tablets Used}

The tablet provided to students is of the type: Samsung Tab A6 T280. Its characteristics are as follows:

TABLE I: CHARACTERISTICS OF THE TABLETS SUPPLIED

\begin{tabular}{ll}
\hline \hline Screen size & $177.7 \mathrm{~mm}\left(7^{\prime \prime}\right)$ \\
\hline Resolution & WXGA $(1280 \times 800)$ TFT LCD \\
Processor & Quad Core Processor $1.3 \mathrm{GHz}$ \\
RAM & $1.5 \mathrm{~GB}$ \\
Internal storage & $8 \mathrm{Go}$ \\
Battery & $4000 \mathrm{mAh}$ \\
Camera & $5.0 \mathrm{MP} \mathrm{AF}+2.0 \mathrm{MP}$ VT \\
Operating system & Android 5.1 Lollipop \\
Connectivity & WiFi, Bluetooth, GPS \\
Dimensions & $186,9 \times 108,8 \times 8,7 \mathrm{~mm}$ \\
Weight & $283 \mathrm{~g}$ \\
\hline \hline
\end{tabular}

\section{RESUlts}

We focused in this study on 7 axes:

\section{A. Perception of Utility}

To question the acceptability of teachers in terms of perceived use, with reference to Davis' TAM model [15], [16] we used 3 items which are based on their own perceptions.

Item 1: Do you find that the use of tablets in the act of teaching and learning has improved your teaching practice?

Item 2: Do you find that learners have an interest in working with tablets?

Item 3: Do you think that the use of tablets by learners focuses their attention on assigned tasks?

Cronbach's alpha for these 3 items is 0.869 . This value is greater than 0.7 , which has assured us of the reliability of this group of items [17]. For item 1, over 54\% confirmed they strongly agree and over $8 \%$ agreed, compared to $20.8 \%$ who did not. For item 2, 50\% of teachers strongly agree and 20.8 agree versus 6.2 who do not. And for item 3, 54.2\% strongly agree and 8.3 agree versus 29.2 who do not. These results point to the fact that the majority of primary school teachers have perceived an educational benefit in the use of tablets. Therefore, they stood up for the integration of this tool into classroom practice. The answer to item 12 of the questionnaire "Would you like to generalize the use of tablets for all primary school learners?" Confirms this result: $83.3 \%$ agree, compared to $16.7 \%$ who do not. This result is also confirmed by the response to item 14 where $78.8 \%$ of respondents chose the digital tablet as an adapted tool for learning for primary school learners.

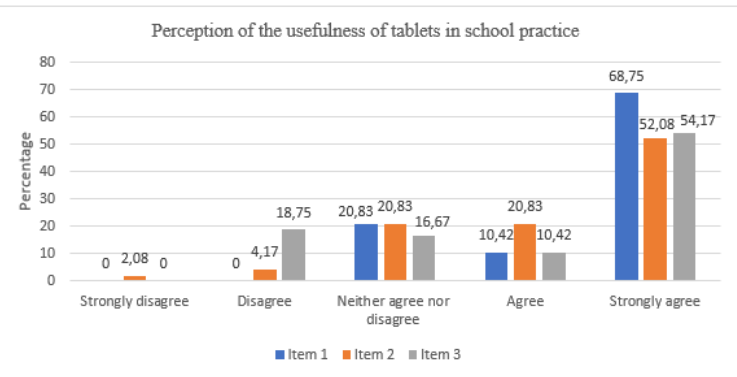

Fig. 4. Perception of the usefulness of tablets in school practice.

\section{B. Impact of Teacher Training on Their Acceptability of Tablets in Classroom Practice}

First, we looked for a possible relationship between training teachers to use tablets and improving their teaching practices. We used the chi-square test by grouping the modalities, and weighting the observations with the "gender" variable. The bond strength between the two variables was verified by Cramer's V coefficient. We found the following results:

TABLE II: CORRELATION BETWEEN TEACHER TRAINING AND IMPROVED TEACHING PRACTICES

\begin{tabular}{ccccc}
\hline \hline & $\begin{array}{c}\text { Pearson } \\
\text { chi-square }\end{array}$ & ddl & $\begin{array}{c}\text { Sig. approx. } \\
\text { (bilateral) }\end{array}$ & Cramer's V \\
\hline Value & 12,557 & 2 & 0,002 & 0,384 \\
\hline \hline
\end{tabular}

The p-value is equal to 0.002 . It is well below the commonly accepted threshold of 0.05 . This proves that the two variables are well correlated. The strength of this correlation is demonstrated by Cramer's V coefficient which is 0.384 . This indicates a considerable force binding, which shows the existence of a strong positive impact of teacher training on improving their teaching practices.

Secondly, we looked for the possible correlation between teachers' perception of improvement in teaching practices through the use of tablets and their desires to use these artefacts in classroom practice. The search for this correlation was controlled by the variable: "training in the use of tablets". Using the chi-square test in this case revealed two cells with a theoretical size of less than 5. This is why we opted for Fisher's exact test. The strength of a possible relationship is calculated by the coefficient $\mathrm{V}$. We found the following results:

TABLE III: CORRELATION BETWEEN PERCEIVED IMPROVEMENT IN TEACHING PRACTICES AND DESIRE TO USE TABLETS IN THE ClASSROOM

\begin{tabular}{cccc}
$\begin{array}{c}\text { Training in the use } \\
\text { of tablets }\end{array}$ & $\begin{array}{c}\text { Fisher's } \\
\text { exact test }\end{array}$ & Sig. Exact & $\begin{array}{c}\text { Cramer's V } \\
\text { coefficient }\end{array}$ \\
\hline No & 36,953 & 0,000 & 1,000 \\
Yes & 5,644 & 0,090 & 0,386 \\
Total & 44,718 & 0,000 & 0,763 \\
\hline \hline
\end{tabular}

These results confirm that the acceptance of the use of digital tablets in classroom practice is strongly linked to the perception of the improvement in teaching practices due to the use of this artefact $(\mathrm{V}=0.763)$. And that relationship is very influenced by whether or not attended training in tablets. All of the untrained teachers did not perceive any improvement in their teaching practices. Therefore, they opposed the integration of tablets in pedagogical practice. But those who were trained in the use of these artefacts did not oppose this integration.

\section{Frequency of Use}

The results obtained show that the tablets were not used frequently in classroom practice, since $62.5 \%$ of teachers only used them once or twice a week (Fig. 5). And the duration of use was fifteen to forty-five minutes per week for $66.67 \%$ of respondents (Fig. 6) on an average hourly learning volume of 28 hours. The responses provided in the interviews explained this to us by the existence of several obstacles and limitations that hindered the integration of these tablets on a large scale. (See 'obstacles and limits' below). 


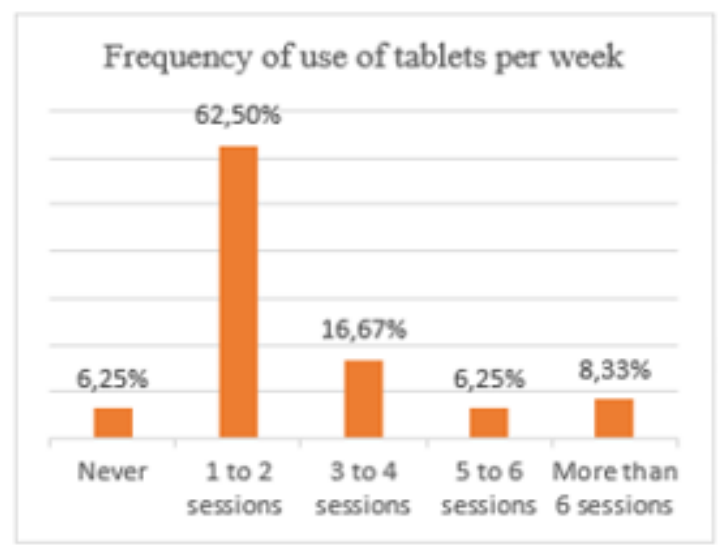

Fig. 5. Frequency of use of tablets per week.

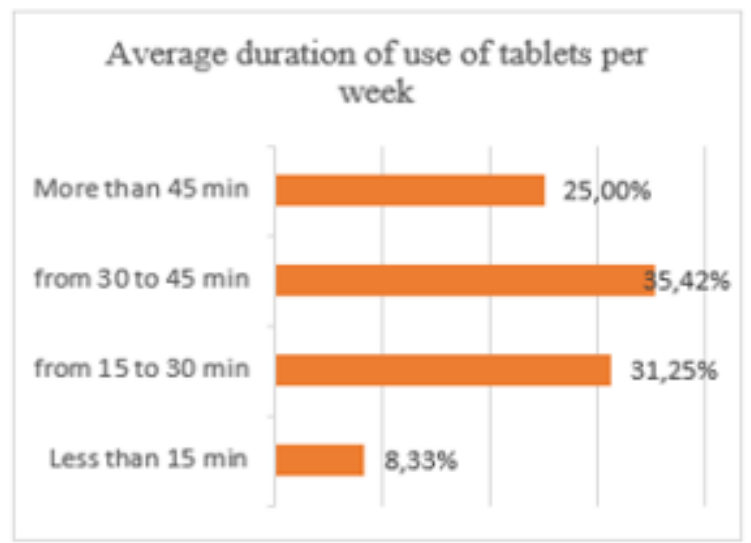

Fig. 6. Average duration of use of tablets per week.

\section{Space of Use}

The majority of survey respondents $(81.3 \%)$ stated that tablet use was restricted to the classroom and under their direction. And $20.8 \%$ of teachers said that they allow a free use, but always within the classroom. They explained this in the interviews by the protection of the safety of the devices and the fear of possible damage which could affect their responsibilities. The responses also showed that only $4.2 \%$ of teachers allowed the use of these artefacts during educational outings, which are generally under the supervision of teachers. These respondents stated that they used the tablets with their learners outside of the classroom during extracurricular activities, such as awareness activities; in this case the prevention of road accidents and cybercrime.

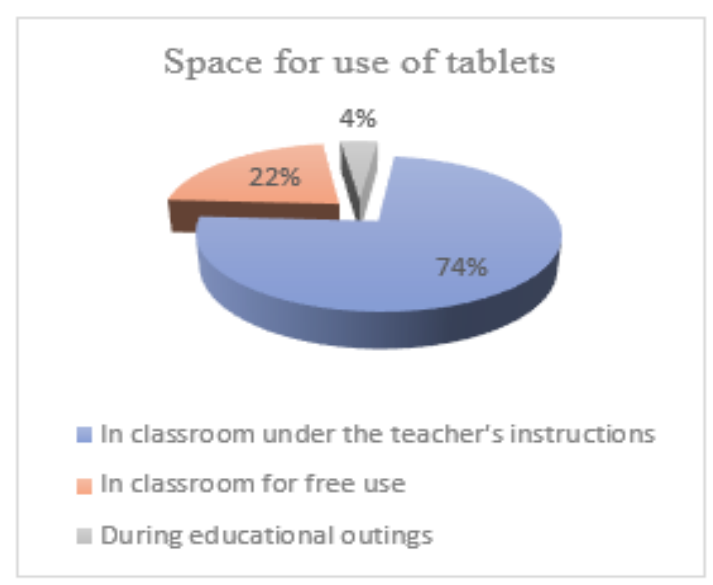

Fig. 7. Space for use of the tablets.

In short, all those questioned agreed that students were not allowed to use the tablets except in the presence of their teachers. Therefore, other dimensions of use based on the ubiquity and mobility of this artefact have been shown to be absent [1].

\section{E. Type of Educational Activity}

Activities related to the use of tablets in class were divided between, help with course support $(54.17 \%)$, evaluation activities (52.08\%), remediation activities (45.83\%) and educational games $(64.58 \%)$. Other types of use such as extracurricular activities represent only $8.33 \%$.

This diversification of activities is marked by a slight trend towards educational games. In interviews, respondents explained that learners liked to be entertained by educational games installed on tablets, and teachers exploited this dimension as a diversification of teaching styles and methods. Furthermore, games applications were more easily found compared to other digital resources.

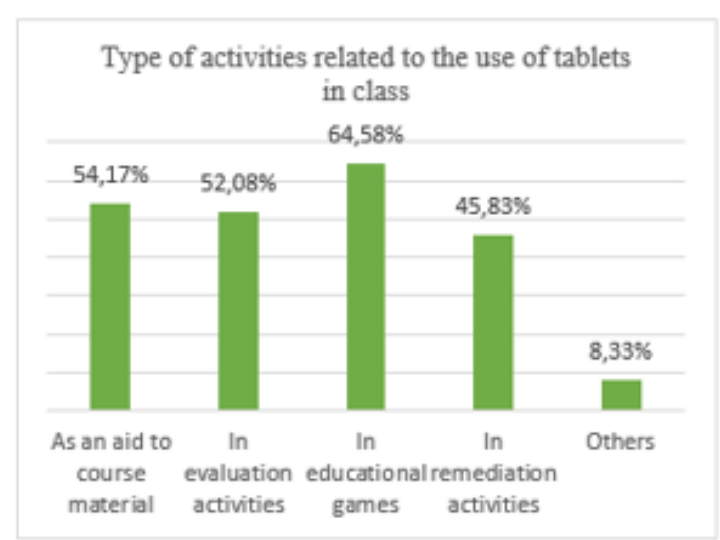

Fig. 8. Type of activities related to the use of tablets in classroom.

\section{F. Distribution of Educational Activities According to School Levels and to the Subjects Taught}

The levels that have benefited the most from using tablets in the classroom are: Level 1, Level 2 and Level 3. The teachers surveyed mentioned that digital resources for the other three levels are rarer than for the first ones. This observation was explained by the change in school curriculum which should affect these levels. This has pushed innovative teachers, one of the main sources of creation of digital resources, not to produce in these levels.

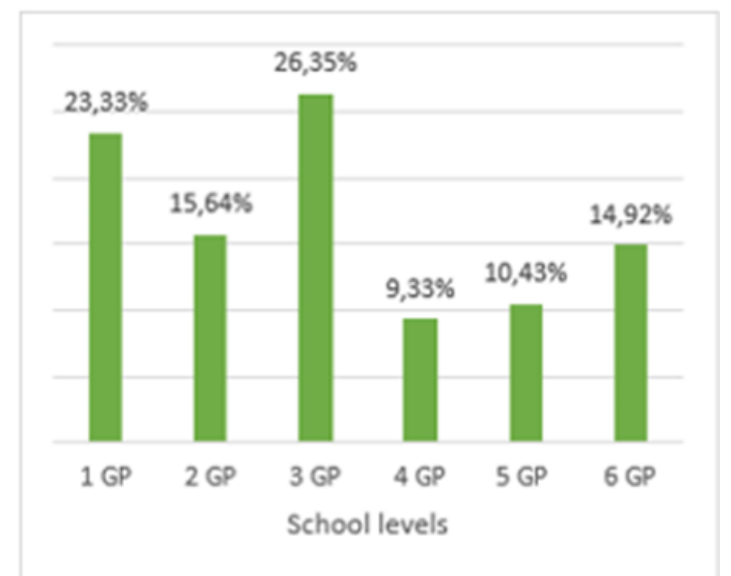

Fig. 9. Distribution of educational activities by school level.

Regarding the subjects that have integrated the tablet in 
teaching-learning, the results gave us in the first place, languages $(44.73 \%)$, followed by sciences and mathematics $(28.43 \%)$, social subjects $(18.88 \%)$, and finally coding with $7.96 \%$. Again, it was the availability of adequate digital resources in each subject that dictated these results.

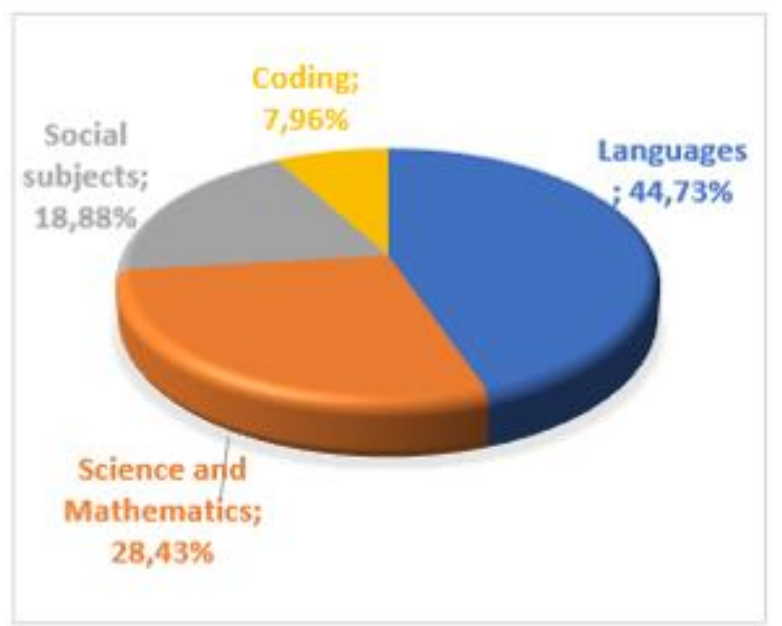

Fig. 10. Repartition of educational activities by subjects taught.

\section{G. Obstacles and Limits}

Participants in this research identified several obstacles that hindered the efficient integration of tablets into classroom practice. We have classified them under two main categories:

\section{1) Technical limits}

The participants noted a very insufficient number of tablets to be able to benefit greatly on the educational plan. "They gave us 10 tablets for more than 600 students. This is not even enough for a class where the average in our school is 34 students ". "The major drawback that I found is that the number of tablets is insufficient." This note was unanimous among all participants. The majority of the students who used it worked with a tablet for 2 to 4 learners.

Other participants emphasized the tool's storage capacity. "The tablet's memory is insufficient to store a sufficient number of educational applications"."... this problem arose more and more when we wanted to load applications covering the six grades of primary school." The tablets provided to the beneficiary schools have a storage capacity of $8 \mathrm{~GB}$. This storage capacity has been found to be insufficient for a use that covers all primary levels.

Furthermore, and unanimously, all respondents agreed that digital resources were insufficient, especially at the fifth and sixth grade levels. "We do not have enough digital resources", "we need resources that are consistent with the Moroccan primary curriculum". Most of the resources used come from the productions of innovative teachers, who did not produce enough in last two levels, because their programs were subject of revisions scheduled by the ministry.

The lack of internet access was mentioned by a large part of the participants. This has hampered their use of tablets in information retrieval practices and the use of the Internet for educational purposes.

\section{2) Institutional limits}

The majority of questionnaire respondents, and all of the interview respondents, agreed that training on the use of tablets is necessary for its integration into classroom practices. This training should be on two levels: technical and educational. $38.3 \%$ of survey respondents said they had no training in the use of digital tablets. And $40 \%$ of the untrained did not see any improvement in their classroom practices using tablets. Those who took the training said that it was insufficient for an efficient integration of this technology in primary school: "I followed 3days training which was mainly focused on the technical side". "I lack a solid training in the educational use of tablets, which is why I mainly use it in educational games".

Furthermore, respondents said that the high number of learners per class, compared to the number of tablets provided, was a handicap for efficient use of tablets. 2 to 4 learners per tablet created a situation where only one student in the group handled the artefact while the rest were just spectators.

Added to all this is another organizational hurdle: teachers have said they are not allowed to let learners take the tablets home. After each use which should be under their supervision, the teachers had to return the suitcase of the tablets to the school principal. This restriction of use in the classroom has hampered the use of this tool in one of its strong educational benefits: ubiquitous learning [1].

\section{DISCUSSION}

The results of this research show us that the use of the tablet in Moroccan primary schools covers all the subjects taught, but remains infrequent and restricted to the classroom. This state of affairs is dictated by two major factors:

- On the one hand, the poor training of teachers in the technical and educational use of tablets: The technical dimension of this training ensures the ease of use of the tool. And the educational dimension ensures a perception of utility for the teacher. These two dimensions are intrinsically linked [1], and give the teacher a good competence towards this artefact and a good understanding of its use at the service of teaching practice, which positively influences the learners [18], [19] . The perception of ease of use and the perception of utility of the tool are decisive in the appropriation of this technology, and influence its frequency of use [1]. This study shows that those who received training in the use of tablets perceived an improvement in their teaching practices, while those who did not master this technology could not use it, and therefore saw no use in this tool.

- On the other hand, the work environment - or facilitating conditions - [16], [20] represent the second factor of efficient integration: a sufficient number of tablets for a job according to the "one to one" model, a satisfactory bank of digital resources in line with school curricula, a reduced number of students per class, the provision of internet for schools ... etc. These working conditions form the logistics allowing the establishment of a favourable ecosystem to benefit from the added value of this technology. This research shows us that despite the acceptance of teachers who have been trained in the subject of tablets, to integrate this tool into their teaching practices, the working conditions hampered this operation. 
This inventory has a double negative impact: on the one hand, it hinders the efficient use of this technology by teachers in classroom practice; and on the other hand, it slows down further research on the use of tablets in teaching-learning in general.

As a result, the integration of the digital tablet and its appropriation within the education system can only be established through continuous training of teachers in the use of this tool at the technical and pedagogical level; and ensuring the working conditions necessary to do this. We have schematized this model of integration of tablets in formal education by deriving it from the Davis [15], [16], [21] as follows:

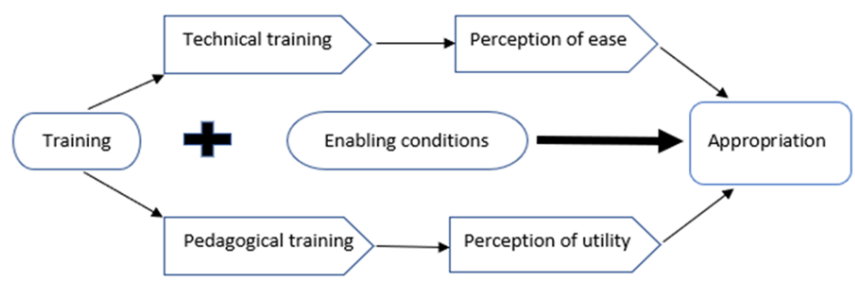

Fig. 11. tablets integration model in formal education.

\section{CONCLUSION}

This research highlights two main factors that influence the integration of digital tablets into classroom practice in Moroccan primary schools: teacher training and the infrastructure of the ecosystem work. The introduction of this tool into the Moroccan education system is only in its infancy, and teachers are little or not trained for this kind of teaching. This research shows that a good mastery of tool technology can only be achieved through solid technical training; and, an efficient integration of this technology into teaching practices can only be achieved through training at the educational level. Furthermore, the creation of a favourable ecosystem for the efficient use of this kind of practice requires the adequate technical and institutional infrastructure, without which the use of this tool will bring more disadvantages than advantages. The study highlights the importance of teacher training in their acceptability of this technology in educational practice. It also elucidates the main obstacles hindering the introduction of the tablet in primary education. However, other factors that can influence the integration of tablets in the classroom context remain to be explored such as learner acceptability, and the real contributions of this technology in teaching and learning in Moroccan primary schools.

\section{CONFLICT OF INTEREST}

The authors declare no conflict of interest.

\section{AUTHOR CONTRIBUTIONS}

El Ayachi Rahali participated in all the phases and stages of the development of the article, from the development of the questionnaire and the interviews to the final drafting. A. Chikhaoui and K. Elkhattabi participated in the elaboration of the questionnaire and the interview questions. They were also responsible for the revision of the French-language article. F. Ouzennou was responsible for communicating with the regional academy to access the schools that participated in the survey. She also participated in the analysis of the data and the translation of the article into English. All authors had approved the final version

\section{REFERENCES}

[1] A. Fiévez and T. Karsenti, "Usages et perceptions des enseignants lors de l'utilisation de la tablette en contexte scolaire," Form. Prof., vol. 26, no. 1, p. 55, 2018, doi: 10.18162/fp.2018.394.

[2] F. Villemonteix, D. Hamon, S. Nogry, A. Séjourné, B. Hubert, and J.-M. Gélis, "Expérience tablettes tactiles à l'école primaire - ExTaTE," p. 88.

[3] K. Melhuish and G. Faloon, "Looking to the future: M-learning with the iPad," Computers in New-Zealand Schools: Learning, Leading, Technology, vol. 22, no. 3, 2010.

[4] K. Ciampa, "Learning in a mobile age: An investigation of student motivation: Learning in a mobile age," J. Comput. Assist. Learn, vol. 30, no. 1, pp. 82-96, Feb. 2014, doi: 10.1111/jcal.12036.

[5] S. Henderson and J. Yeow, "iPad in education: A case study of iPad adoption and use in a primary school," in Proc. 2012 45th Hawaii International Conference on System Sciences, Maui, HI, USA, Jan. 2012, pp. 78-87, doi: 10.1109/HICSS.2012.390.

[6] B. Haßler, L. Major, and S. Hennessy, "Tablet use in schools: A critical review of the evidence for learning outcomes: Tablet use in schools: A critical review," J. Comput. Assist. Learn, vol. 32, no. 2, pp. 139-156, Apr. 2016, doi: 10.1111/jcal.12123.

[7] F. Amadieu and J. Mulet, "Acceptabilité des technologies d'apprentissage mobile: le cas des tablettes," p. 11.

[8] OCDE, Perspectives des politiques de l'éducation 2015: Les réformes en marche, OECD, 2015.

[9] W. Supper, "La fréquence d'utilisation de la tablette numérique à des fins pédagogiques et le rendement scolaire des élèves: le rôle médiateur de la motivation autodéterminée," p. 36, 2019

[10] CSEFRS, "Pour une école de l'équité, de la qualité et de la promotion: Vision stratégique de la réforme 2015-2030," 2015.

[11] C. Baribeau and C. Royer, "L'entretien individuel en recherche qualitative: usages et modes de présentation dans la Revue des sciences de l'éducation," Rev. Sci. L'éducation, vol. 38, no. 1, pp. 23-45, Jun. 2013, doi: 10.7202/1016748ar.

[12] L. Briz-Ponce, A. Pereira, L. Carvalho, J. A. Juanes-Méndez, and F. J. García-Peñalvo, "Learning with mobile technologies - Students' behavior," Comput. Hum. Behav., vol. 72, pp. 612-620, Jul. 2017, doi: 10.1016/j.chb.2016.05.027.

[13] L. J. Cronbach and R. J. Shavelson, "My Current Thoughts on Coefficient Alpha and Successor Procedures," Educ. Psychol. Meas., vol. 64, no. 3, pp. 391-418, Jun. 2004, doi: $10.1177 / 0013164404266386$.

[14] B. Lefèvre and S. Champely, "Methodes statistiques globales et locales d'analyse d'un tableau de contingence par les tailles d'effet et leurs intervalles de confiance," Bull. Sociol. Methodol. Méthodologie Sociol., vol. 103, no. 1, pp. 50-65, Jul. 2009, doi: 10.1177/075910630910300106.

[15] F. D. Davis, "Perceived Usefulness, Perceived Ease of Use, and User Acceptance of Information Technology," MIS Q., vol. 13, no. 3, p. 319, Sep. 1989, doi: 10.2307/249008.

[16] V. Venkatesh and H. Bala, "Technology Acceptance Model 3 and a Research Agenda on Interventions," Decis. Sci., vol. 39, no. 2, pp. 273-315, May 2008, doi: 10.1111/j.1540-5915.2008.00192.x.

[17] J. M. Bland and D. G. Altman, "Statistics notes: Cronbach's alpha," $B M J$, vol. 314, no. 7080, pp. 572-572, Feb. 1997, doi: 10.1136/bmj.314.7080.572.

[18] S. Kontkanen, "Students' experiences of learning with iPads in upper secondary school - A base for proto-TPACK," p. 28.

[19] H. Montrieux, "A qualitative study about the implementation of tablet computers in secondary education: The teachers' role in this process," p. 8,2014

[20] S. Atarodi, A. M. Berardi, and A.-M. Toniolo, "Le modèle d'acceptation des technologies depuis 1986: 30 ans de développement," Psychol. Trav. Organ., vol. 25, no. 3, pp. 191-207, Sep. 2019, doi: 10.1016/j.pto.2018.08.001.

[21] V. Morris, 'User acceptance of information technology: Toward a unified view," MIS Q., vol. 27, no. 3, p. 425, 2003, doi: 10.2307/30036540.

Copyright (C) 2021 by the authors. This is an open access article distributed under the Creative Commons Attribution License which permits unrestricted 
use, distribution, and reproduction in any medium, provided the original work is properly cited (CC BY 4.0).

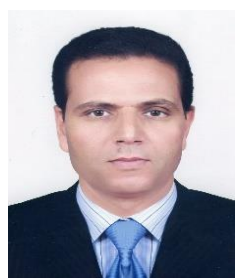

El Ayachi Rahali is a $\mathrm{PhD}$ in science didactics, University Sidi Mohamed Ben Abdellah, USMBA, Fez. And he is a trainer in the regional centre for education and training in Béni Mellal. Morocco. His specialties are Educational technologies and science didactics.

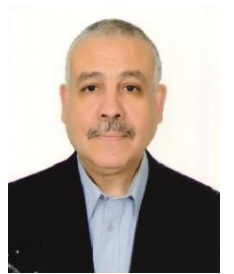

Ahmida Chikhaoui is a professor of Higher Education (PES). University Sidi Mohamed Ben Abdellah, USMBA, Fez, Morocco. His specialties are nuclear physics, computer science and didactics of science.

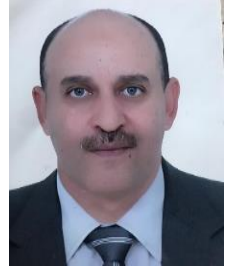

Khalid El khattabi is a professor of Higher Education (PESA) University Sidi Mohamed Ben Abdellah (USMBA), Fes Morocco. His specialties are pedagogy and didactics of physics.

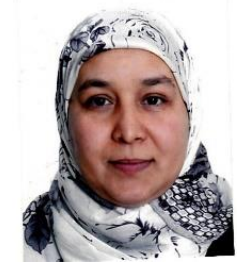

Fatima Ouzennou is a Professor of Higher Education (PA). Trainer in the regional centre for education and training. Fes, Morocco. Her specialties are information and communication technologies in education (ICTE) and didactics. 